\title{
Bond strength of glass-ceramic cemented to a zirconia structure: influence of adhesive cementation strategy
}

\author{
Resistência de união de uma cerâmica vítrea cimentada à estrutura de zirconia: influência da estratégia de união ${ }^{1}$
}

\author{
Gilvan Cutrim TAVARES 2 \\ Renan Macedo Cutrim TAVARES² \\ Milton Edson MIRANDA² \\ Cecilia Pedroso TURSSI² \\ Roberta Tarkany BASTING² \\ Fabiana Mantovani Gomes FRANÇA ${ }^{2}$ \\ Flavia Lucisano Botelho do AMARAL²
}

\section{ABSTRACT}

\section{Objective}

This study evaluated the shear bond strength (SBS) of lithium disilicate glass (LDG) ceramic bonded to a zirconia (Y-TZP), using different cementation strategies.

\section{Methods}

LDG ceramic cylinders were cemented to Y-TZP structure according to the following adhesive system (AS)/resin cement (RC) ( $n=15)$ : U- selfadhesive dual-cure RC; $A M B A R$ - AS containing phosphate monomers (PM) + dual-cure RC; group SBU: PM+Silane/AS + light-cure RC; group ALLB: PMIAS + dual-cure RC. Specimens were subjected to SBS in a universal testing machine $(0.5 \mathrm{~mm} / \mathrm{min})$. Data (MPa) were subjected to one-way ANOVA and Tukey's test $(\alpha=0,05)$.

\section{Results}

The groups SBU and ALLB had significantly higher SBS than those provided by the group $U$, in which the lowest values were observed. For the $A M B A R$ group, intermediate SBS values were found, which did not differ significantly from the values observed in the other groups.

\section{Conclusion}

Regardless of resins cement, the use of adhesives containing phosphate monomers provided superior bond strength than self-adhesive cement.

Indexing terms: Ceramics. Dentin-bonding agents. Resin cements. Shear strength.

\section{RESUMO}

Objetivo

Avaliar a resistência de união por cisalhamento (RU) de uma cerâmica de dissilicato de lítio (CDL) à zircônia (Y-TZP) utilizando diferentes estratégias de cimentação.

\section{Métodos}

Cilindros de CDL foram cimentados à estrutura de Y-TZP de acordo com os seguintes sistemas adesivos (SA)/ Cimentos resinosos (CR) ( $\mathrm{n}=15)$ : U: CR autoadesivo de cura dual; AMBAR: SA contendo monômeros fosfatados (MF) + CR convencional de cura dual; SBU: SA contendo MF/silano + RC de cura fotoativada; ALLB: SA contendo MF/silano + CR de cura dual. Os corpos de prova foram submetidos ao teste de cisalhamento em máquina universal de ensaios $(0.5 \mathrm{~mm} / \mathrm{min})$. Os dados (MPa) foram submetidos a ANOVA a um critério e teste de Tukey $(\alpha=0,05)$.

\section{Resultados}

Observou-se que os grupos SBU e ALLB promoveram valores de RU estatisticamente superiores ao grupo U, no qual observou-se a menor média de RU. Para o grupo AMBAR, valores de RU intermediários foram encontrados, os quais não diferiram dos demais grupos.

\section{Conclusão}

Independente do cimento resinoso, o uso de sistemas adesivos contendo monômeros fosfatados em sua composição promoveram resistência de união superior ao cimento resinoso autoadesivo.

Termos de indexação: Cerâmicas. Adesivos dentinários. Cimentos de resina. Resistência ao cisalhamento.

\footnotetext{
${ }^{1}$ Manuscript based on a master thesis titled: Bond strength of vitreous ceramic cemented to zirconia structure: influence of adhesive strategy cementation". São Leopoldo Mandic Faculty; 2014. 70 p.

${ }^{2}$ Faculdade São Leopoldo Mandic, Curso de Odontologia. Rua José Rocha Junqueira, 13, 13045-755, Swift, Campinas, SP, Brasil. Correspondência para/Correspondence to: FLB AMARAL. E-mail: <flbamaral@gmail.com>.
} 


\section{INTRODUCTION}

In recent years, esthetic demands have caused dental professionals to opt for the use of metal-free ceramics in prosthodontics. The development of leucite, lithium disilicate, zircônia and alumina-reinforced ceramics has allowed the substitution of metallic infrastructures in diverse clinical situations, due to their high flexural and compressive strength, including in areas of masticatory force ${ }^{1-3}$.

The clinical success of prosthetic rehabilitation using metal-free ceramics depends on several factors, with the cementing process being among the most important ${ }^{4}$. While adhesive bonding of a prosthesis, which is the role of the resin cement, influences its clinical performance ${ }^{5}$, these cements have limited use, such as in the case of alumina and zirconia-reinforced ceramics.

Regarding zirconia ceramics, which have a high crystalline content, ${ }^{6}$ conventional procedures such as etching with hydrofluoric acid and application of a silane agent do not yield satisfactory outcome ${ }^{6-7}$. Cementing techniques for zirconia ceramics include surface treatment methods through sandblasting with aluminum oxide and the use of materials that promote a chemical bond to the zirconium dioxide ${ }^{7-9}$.

Nonetheless, zirconia ceramics have been utilized in various clinical situations, such as with implants, a procedure widely used for its esthetic advantages, specifically referring to zirconia abutments. In this type of oral rehabilitation, glass ceramics are indicated for making dental crowns, whether lithium disilicate, or leucite-reinforced glass-ceramic ${ }^{10}$. Thus, adhesive cement is required at two stages: primarily for cementation of the zirconia abutment to the titanium base (TiBase) forming an abutment-hybrid to be screwed to the implant, and then between the zirconia abutment and the glass-ceramic crown.

Another possible restorative approach, which involves the cementing of the glass-ceramic to the zirconia structure, is in multi-element fixed prostheses that have been prepared by the multilayer process where, through the CAD/CAM system, a zirconia infrastructure and a glass-ceramic suprastructure, both adhesively cemented to one another, form a single structure, which can then be cemented to the abutments ${ }^{11}$. In both cases, cementation can be performed with either dual or light-cured self-adhesive or conventional resins ${ }^{12-14}$.
Self-adhesive resin cements, which consist almost exclusively of zirconium oxide-based ceramics, contain phosphate monomers that chemically bond to zirconium and may exhibit higher bond strength values after sandblasting with aluminum oxide when compared to conventional cements ${ }^{14}$. Furthermore, selfadhesive resin cements have the advantage of needing no bonding agent or other pre-treatment of the tooth, in addition to reducing post-cementing sensitivity ${ }^{14}$.

Conventional dual resin cements have the advantage of exhibiting adequate mechanical properties and are indicated to cement restorations made with materials that inhibit sufficient light energy from being transmitted to the cement ${ }^{15}$. Light-cured resin cements, on the other hand, have a longer working time in order to obtain perfect seating of the ceramic veneer, and in addition allow for careful removal of excess prior to polymerization ${ }^{16}$, as well as obtaining a higher color stability when compared to dual cement ${ }^{17}$. Therefore, both the selection of material and technique constitutes important steps in the cementing of metalfree ceramics ${ }^{15}$.

Furthermore, dental material manufacturers have developed zirconia primers ${ }^{18}$ containing phosphate monomers, which allow bonding of conventional resin cements (i.e. those that are not self-adhesive) to the zirconia structure, whether self-cured, light-cured or dual ${ }^{18}$. The development of such primers confirms the importance of maximizing the benefits of adhesive cementation in clinical cases where a bond between glass-ceramic and zirconia-ceramic is needed. The improved bond strength between resin cement and zirconia provided by the phosphate monomercontaining primers has made it possible to cement glass-ceramic veneers, overlays and crowns to zirconia structures $^{19}$.

However, scientific research on the adhesive bonding that joins glass-ceramic to zirconia is still lacking, with few studies to date that have investigated the use of universal one-bottle adhesive systems containing phosphate monomers as a bonding strategy.

Therefore, this study aimed to evaluate bond strength between lithium disilicate glass-ceramic and Yttrium-stabilized tetragonal zirconia polycrystalline (Y-TZP), according to cementation strategy, using a universal one-bottle adhesive prior to application of dual and light-cured conventional resin cements and dual self-adhesive cement. 


\section{METHODS}

This study was approved by the Research Ethics Committee of the São Leopoldo Mandic Dental School, registration no. 2013/0067.

\section{Experimental design}

The experiments were designed as randomized and unifactorial. The factor under investigation was the cementation strategy/system on 4 levels:

- Group U: Dual-cure self-adhesive cement (U200 Automix - 3M ESPE, USA);

- Group AMBAR: Adhesive system containing phosphate monomers (Ambar - FGM, Brazil) + dual resin cement (Duo Link Universal - Bisco, USA);

- Group SBU: universal adhesive systems containing phosphate monomers (Scotchbond Universal Adhesive - 3M ESPE, USA) + light-activated resin cement (RelyX Veneer - 3M ESPE, USA);

- Group ALLB: universal adhesive system containing phosphate monomers (All-Bond universal Bisco, USA) + dual resin cement (Duo Link Universal - Bisco, USA).

The experimental units consisted of 60 zirconia ceramic cylinders and 60 lithium disilicate ceramic cylinders, randomly distributed among the four groups. The response variable was shear bond strength $(\mathrm{MPa})$, which was continuous and quantitative. The failure mode was evaluated qualitatively using a light microscope (40X).

\section{Sample preparation}

Sixty Y-TZP (yttrium-stabilized tetragonal zirconia polycrystals - Zirkonzahn - Italy) ceramic cylinders were produced, measuring $4 \mathrm{~mm}$ in diameter and $4 \mathrm{~mm}$ in height. The ceramic cylinders were mounted in PVC cylinders (Tigre, Brazil) that measured $25 \mathrm{~mm}$ in diameter with a lumen of $20 \mathrm{~mm}$ in diameter and $5 \mathrm{~cm}$ in height. Self-curing acrylic resin (JET Campo Limpo Paulista, SP, Brazil) was poured into the ceramic cylinder filling it completely.

The surface of the ceramic cylinders was polished using silicon carbide sandpaper at \#220, \#360, \#600, \#800 and \#1200 grains (Acqua Flex, Norton, Brazil) on a rotating electric polisher (AROPOL$2 \mathrm{~V}$, Arotec, Brazil) under constant water irrigation. All cylinders were cleaned for 5 minutes in an ultrasonic bath (Kondortech, São Paulo, Brazil) filled with distilled water and then dried with oil-free jets of air. The zirconia surfaces were sandblasted with 50-micron particles of aluminum oxide from a distance of $10 \mathrm{~mm}$ for 10 seconds at 46-55 psi of pressure (micro-jet BioArt - Sao Paulo, Brazil).20 The ceramic samples were cleaned with water jet sprays for 20 seconds using a 3 -in-1 syringe. All cylinders were immersed in the ultrasonic bath again for 5 minutes and dried with oilfree jets of air.

For cementation onto the zirconia cylinders, sixty glass-ceramic lithium disilicate cylinders measuring $1.5 \times 5 \mathrm{~mm}$ (Figure 4) were obtained using wax wires (Cera Babinete, Maringá - PR - Brazil) via the lost-wax technique and subsequent injected with the IPS E.max Press system (Ivoclar, Schaan - Liechtenstein). The cylinders were cut $5 \mathrm{~mm}$ long using a precision cutter (ELQUIP - Sao Paulo, Brazil) and a diamond disc (EXTEC - Enfield, Connecticut, USA). All low quality cylinders (showing chips or cracks) were discarded. The good cylinders were etched with $10 \%$ hydrofluoric acid for 20 seconds, washed thoroughly for 20 seconds with water and dried with compressed jets of air. A silane layer was applied (Prosil - FGM, Brazil) and left to dry for 20 seconds.

An adhesive tape with a $1.5-\mathrm{mm}$ diameter perforation was fixed over the center of the zirconia surface in order to standardize the cementing area.

The 60 zirconia and lithium disilicate cylinders were randomly divided into 4 groups $(n=15)$, according to the cementation system (adhesive / resin cement) to be applied at the time of cementation.

\section{Cementation of the specimens}

- Group U: dual-cure self-adhesive cement (RelyX U200 - 3M ESPE, USA);

- Group AMBAR: adhesive system containing phosphate monomers (Ambar - FGM, Brazil) + dual resin cement (Duo Link Universal - Bisco, USA);

- Group SBU: universal adhesive system containing phosphate monomers (Scotchbond Universal Adhesive - 3M ESPE, USA) + light-cure resin cement (RelyX Veneer - 3M ESPE, USA);

- Group ALLB: Universal adhesive system containing phosphate monomers (All-Bond Universal Bisco, USA) + dual resin cement (Duo Link Universal - Bisco, USA).

The resin cements tested, as well as their composition are described in Table 1. 
Table 1. Description, composition, manufacturer and batch of adhesive cementation materials

\begin{tabular}{|c|c|}
\hline Materials batch & Composition \\
\hline $\begin{array}{l}\text { Rely } \mathbf{X} \text { U200 } \\
\text { self-adhesive dual resin cement }\end{array}$ & $\begin{array}{c}\text { Base: glass powder treated with silane, 2-propenoic acid, (TEGDMA), silane treated silica, glass } \\
\text { fiber, sodium persulfate and per-3,5, 5-trimethyl hexanoate t-butyl. }\end{array}$ \\
\hline batch: 503267 & $\begin{array}{l}\text { Catalyst: glass powder treated with silane, substitute dimethacrylate, silica-silane treated, sodium } \\
\text { p-toluenesulfonate, 1-benzyl-5-phenyl-acid barium, calcium, 1,12-dodecane dimethacrylate, } \\
\text { calcium hydroxide, and titanium dioxide. }\end{array}$ \\
\hline \multicolumn{2}{|l|}{ Ambar Universal } \\
\hline Light-curing adhesive system & $\begin{array}{c}\text { Methacrylate monomers (UDMA and MDP), photoinitiatiors, co-initiators, stabilizers, inert silica } \\
\text { nanoparticles and ethanol. }\end{array}$ \\
\hline \multicolumn{2}{|l|}{ batch: 090513} \\
\hline \multicolumn{2}{|l|}{ Scotchbond Universal Adhesive } \\
\hline Universal light-cured adhesive system & $\begin{array}{l}\text { MDP, dimethacrylate resins, HEMA, methacrylate-modified polyalkenoic acid copolymer, filler, } \\
\text { ethanol, water, initiators, silane }\end{array}$ \\
\hline \multicolumn{2}{|l|}{ batch: 507329} \\
\hline \multicolumn{2}{|l|}{ RelyX Veneer } \\
\hline Light-curing resin cement & BisGMA, TEGDMA, zirconia / silica filler. \\
\hline \multicolumn{2}{|l|}{ batch: 507329} \\
\hline \multicolumn{2}{|l|}{ Universal Link Duo- } \\
\hline Dual resin cement & Base: Bis-GMA, triethyleneglycol dimethacrylate, urethane dimethacrylate, glass filler. \\
\hline batch: 1300001652 & Catalyst: Bis-GMA, triethyleneglycol dimethacrylate, glass filler. \\
\hline \multicolumn{2}{|l|}{ All Bond Universal } \\
\hline Light-curing universal adhesive system & MDP, bis GMA, HEMA, ethanol, water, initiators \\
\hline \multicolumn{2}{|l|}{ batch: 1300001208} \\
\hline \multicolumn{2}{|l|}{ Prosil } \\
\hline Silane & 3-Methacryloxypropyltrimethoxysilane, Ethanol, Water \\
\hline batch: 050912 & \\
\hline
\end{tabular}
dihydrogenphosphate; BISGMA: bisphenol A diglycidyl ether dimethacrylate.

For group $U$, the dual self-adhesive resin cement U200 (3M ESPE) was mixed for 20 seconds with a spatula and applied directly onto the zirconia using a dental probe. The lithium disilicate cylinder was then positioned over the central portion of the zirconia surface using a surveyor (Bio Art, Sao Carlos, SP, Brazil) to allow specimen settling under uniform pressure. Cement excess was removed with a microbrush and light-cured for 20 seconds on each quadrant.

For group AMBAR, Ambar Universal adhesive system (FGM) was applied with a microbrush on the zirconia cylinders, gently dried with jets of air for 5 seconds and light-cured for 20 seconds. The zirconia was applied to the resin cement Duo Link (Bisco), which was mixed for 20 seconds with a spatula and applied to the zirconia surface with a probe. The ceramic cylinder was positioned over the central portion of the zirconia cylinder using a surveyor (Bio Art, San Carlos, SP, Brazil), as previously described. The same procedures were performed for groups SBU (Scotchbond Universal Adhesive + Relyx Veneer) and ALLB (All Bond Universal + Duo-Link Universal).

Polymerization was achieved using a light emitting diode equipment (LED KAVO, Kavo, Joinville, Brazil). Light intensity was maintained at approximately $600 \mathrm{mw} / \mathrm{cm} 2$ and verified prior to cementation of each group using a radiometer (Newdent - Ribeirão Preto / SP / Brazil). The cemented specimens were stored in an incubator at $37^{\circ} \mathrm{C}$, in relative humidity for 48 hours.

\section{Shear bond strength test}

For the shear bond strength test, the specimens were fixed to a specific device mounted on a universal testing machine (EMIC - S. J dos Pinhais, Paraná, Brazil) 
and submitted to shear bond strength testing at a speed of $0.5 \mathrm{~mm} /$ minute. The values in Newton $(\mathrm{N})$ were converted into $\mathrm{MPa}$ by dividing the force $(\mathrm{N})$ at failure by the adhesion surface area $(1.76 \mathrm{~mm} 2)$.

\section{Analysis of failure patterns}

Following the shear bond strength test, the samples were analyzed for failure mode under a stereomicroscope (Model: EK3ST, CQA, Eikonal, São Paulo, SP, Brazil) at 40 times magnification and classified as: cohesive failure - when the failure occurred in the ceramic material: zirconia or lithium disilicate; adhesive failure - when in the adhesive interface and mixed failure - when the two previous situations occurred within the same specimen.

\section{Statistical analysis}

Following checks for compliance with normality and homogeneity of variance, the data was analyzed using one-way analysis of variance and the Tukey test. The failure mode was presented descriptively.

All statistical calculations were performed on
SPSS 20 (SPSS Inc., Chicago, IL, USA) and the significance level was adopted at $5 \%$.

\section{RESULTS}

Table 2 presents the descriptive analysis and results of the Tukey test, in terms of the means and standard deviations of the values obtained using different cementation systems (adhesive / resin cement).

One-way analysis of variance revealed a significant difference between the bond strength values of the cementing systems analyzed $(p=0.001)$. Tukey test showed that when the Scotchbond Universal Adhesive was combined with RelyX Venner resin cement, or the All Universal Bond adhesive was used combined with the Duo-Link Universal cement, significantly higher values were obtained than when the U200 Automix cement was used (Table 2). In the group where the Ambar adhesive was combined with the Duo-Link Universal cement, bond values were intermediate and did not differ significantly from those observed in the other groups (Table 2).

In the group where cementation was performed

Table 2. Means and standard deviations of the MPa values, according to cementation system (adhesive / resin cement).

\begin{tabular}{lc}
\hline Cementation system & Mean (standard deviation) \\
\hline RelyX U200 & $10.22(6.26) \mathrm{B}$ \\
Ambar + Duo Link Universal & $14.93(8.34) \mathrm{AB}$ \\
$\begin{array}{l}\text { Scotchbond Universal Adhesive + } \\
\text { RelyX Veneer } \\
\text { All Bond Universal + Duo-Link }\end{array}$ & $19.58(8.86) \mathrm{A}$ \\
Universal & $21.93(6.94) \mathrm{A}$ \\
\hline
\end{tabular}

Mean followed by capital letter indicates a significant difference between cementing systems.

using U200 Automix cement, 93\% of the failures were classified as adhesive, while in the other groups, mixed failures predominated, which, depending on the cementation system, represented $67-93 \%$ of failures (Figure 1). 


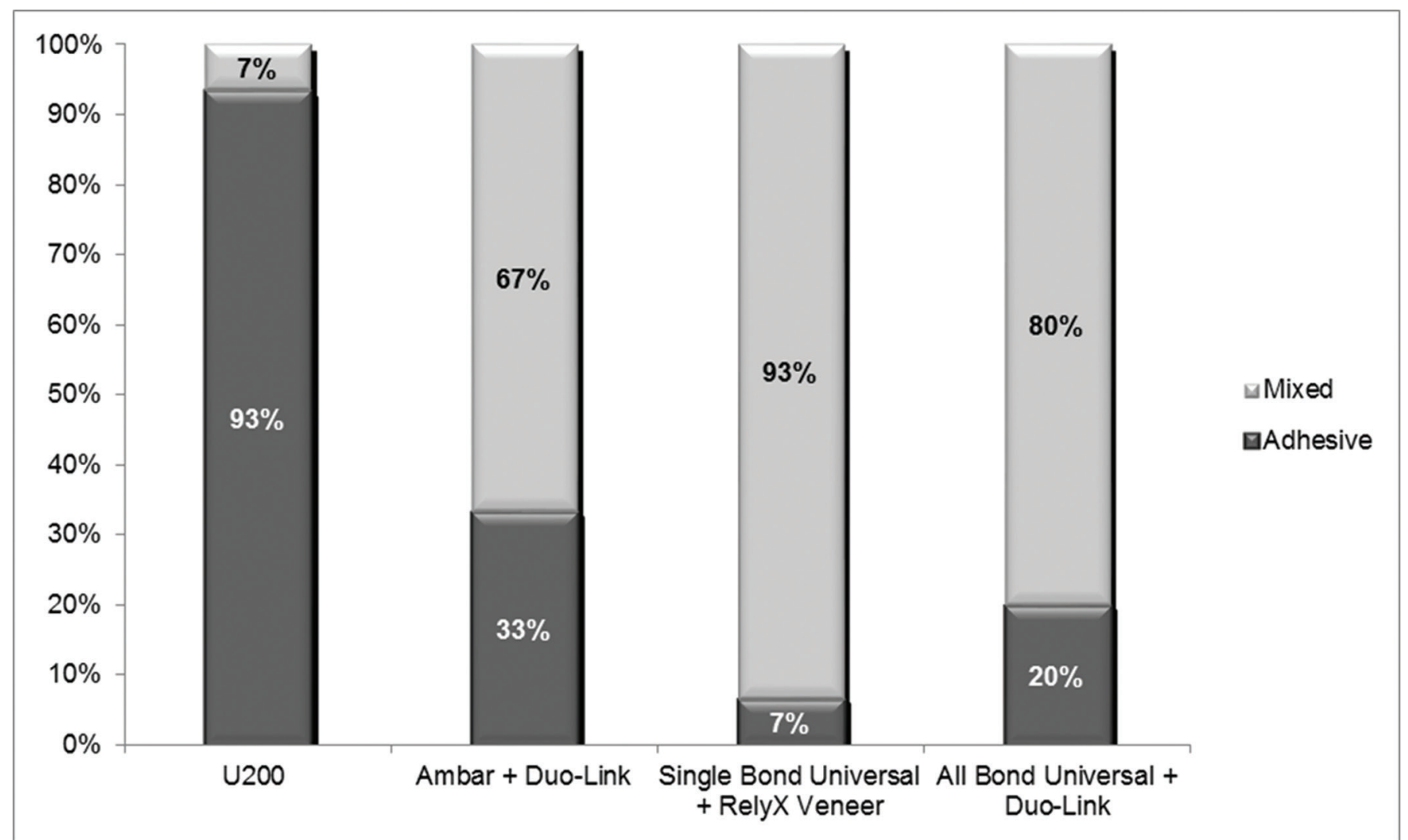

Figure 1. Bar chart showing failure mode according to the cementation system (adhesive / resin cement).

\section{DISCUSSION}

The use of zirconia in dentistry is indicated in the process of crown and fixed bridge preparation, using the CAD/CAM technique ${ }^{21}$. Zirconia has gained its place due to its mechanical property, which is the highest among dental ceramics ${ }^{19,21}$, allowing its use in areas of masticatory force ${ }^{1-3}$.

However, the use of zirconia ceramic for the cementing process is still debatable, due to its high crystalline content, which prevents conditioning of the zirconia by hydrofluoric acid, as well as rendering the application of the silane agent inefficient ${ }^{6-7}$. Therefore, to overcome this hurdle other surface treatments, such as aluminum oxide blasting, silica coating and silanization ${ }^{8,22-24}$ have been proposed. Additionally, a number of studies $18,24-28$ have reported that resin cements, silanes, primers and phosphate monomer-containing adhesives should be indicated for the zirconia cementation. Thus, this study aimed to evaluate the bond strength of lithium disilicate glass-ceramic to the Y-TZP zirconia ceramics using different cementation systems with universal one-bottle phosphate monomer-containing adhesives and comparing them to self-adhesive resin cement.

The shear bond strength test was used to evaluate the bond strength between lithium disilicate glass-ceramic and zirconia ceramic. Despite Mirmohammadi et al. ${ }^{20}$ challenging the ability of shear bond strength testing to detect small differences, the bond strength method described in this study was approved by the ISO and has been widely used by other authors 18,22,24-25,27-29. Aluminum oxide blasting was performed to surface treat the zirconia cylinders, which was applied in a standardized fashion with respect to particle size and blast distance. This technique was proposed based on a literature search, which revealed an improved flexural8 and bond strength ${ }^{22,29}$ following aluminum oxide blasting. Yun et al. ${ }^{28}$ concluded that the use of metal primers and resin cements alone are not sufficient for a long-lasting bond with Y-TZP zirconia ceramic, and it is therefore necessary to perform aluminum 
oxide blasting to improve bond strength. Furthermore, the use of aluminum oxide blasting has also been described in several studies $18,20,23,25-26,29$.

Aboushelib et al. ${ }^{19}$ observed that the bond strength of cement to zirconia can be significantly improved by a combination of surface conditioning and the use of primers for zirconia, such as MDP. This result can be confirmed by the findings of groups SBU (19.58 $\mathrm{MPa})$ and ALLB (21.93 MPa) of the present study, where a Bis-GMA light-curing resin cement was used together with a universal one-bottle adhesive containing MDP and silane, and a Bis-GMA-based dual resin cement (Universal Link Duo) was combined with a new universal one-bottle light-curing adhesive containing MDP and silane (All Universal Bond), respectively, which were not significantly different from one another. This result may be explained by the fact that universal one-bottle adhesive systems containing MDP and silane chemically interact with metal oxides, such as zirconium oxide, creating secondary forces of attraction (Van der Waals forces) or hydrogen bonds at the resin cement/zirconia interface ${ }^{30}$. These interfacial forces improve the wettability of the Y-TZP zirconia surface, allowing an improved interlacing of the cement on the surface roughness, which is promoted by blasting the zirconia surface. These results corroborate those found in the literature ${ }^{18-19,24,27-30}$. The AMBAR group, which used the MDP-based adhesive and methacrylate monomers in conjunction with Bis-GMA-based Duo Link Universal resin cement, presented intermediate adhesion values (14.93 $\mathrm{MPa}$ ) that were not statistically significant when compared to the U200 control group (10.22 MPa), where a selfadhesive resin cement containing active acid monomers was used, which is also indicated for cementation of zirconia ceramic. The AMBAR Group was not significantly different the from SBU (19.58 MPa) and ALLB (21.93 $\mathrm{MPa}$ ) groups. For all groups where the adhesive strategy involved the use of an MDP-containing system (SBU, AALB and $A M B A R$ ), mixed type failures were most common, which may be a reflect of better bond strength in these groups, since the failures were not only at the interface, but also involved the ceramic and/or resin material.

\section{REFERENCES}

1. Pittayachawan P, McDonald A, Petrie A, Knowles JC. The biaxial flexural strength and fatigue property of Y-TZP Lava dental
Surface treatment has been reported as insufficient for an efficient bonding of resin cement to zirconia ceramic $^{22}$. This statement supports the results of the U200 control group of the present study, in which lower bond strength values were obtained. One may speculate that the RelyX U200 cement failed to establish an effective bond between the zirconia and lithium disilicate ceramics, despite it being self-adhesive and containing both active acid monomers and silane. This result was confirmed by a high rate of adhesive type failures (93\%) in this group, and is consistent with results from previous studies ${ }^{18,29}$. However, it is worth noting that the bond results obtained in the U200 group did not differ significantly from the AMBAR group, in which an MDP-containing adhesive was used, in addition they were two-times higher than the minimum bond values established by the ISO (5.0 MPa).

Based on the analysis of these results, an adhesive system to cement lithium disilicate glass-ceramic to Y-TZP zirconia ceramic is always recommended, with the universal one-bottle MDP-containing adhesive also being indicated.

\section{CONCLUSION}

Adhesive strategy influences the bond strength of glass-ceramic to Y-TZP zirconia ceramic, in that the use of a universal one-bottle adhesive that contains MDP in combination with light-cured or dual resin cements had higher bond strength values than when self-adhesive cement was used alone.

\section{Collaborators}

GC TAVARES ran the experiment and wrote the manuscript. RMC TAVARES participated on experiment and manuscript revision. MM MIRANDA critically revised and wrote the manuscript. CP TURSSI performed statistical analysis and wrote the manuscript. RT BASTING and FMG FRANÇA helped to interpret data and revised the manuscript. FLB AMARAL supervised the design and execution of experiment and performed corrections on manuscript.

ceramic. Dent Mater. 2007;23(8):1018-1129. doi: 10.1016/j. dental.2006.09.003

2. Tsalouchou E, Cattel MJ, Knowles JC, Pittayachawan P, McDonald A. Fatigue and fracture properties of yttria partially stabilized 
zircônia crown systems. Dent Mater. 2008;24(3):308-318. doi: 10.1016/j.dental.2007.05.011

3. Pittayachawan P, McDonald A, Young A, Knowles JC. Flexural strength, fatigue life, and stress-induced phase tranformation study of Y-TZP dental ceramic. J Biomed Mater Res B Appl Biomater. 2009;88(2):366-377. doi: 10.1002/jbm.b.31064

4. Cavalcanti AN, Foxton RM, Watson TF, Oliveira MT, Giannini M, Marchi GM. Y-TZP ceramics: key concepts for clinical application. Oper Dent. 2009;34(3):344-51. doi: 10.2341/08-79.

5. Ernst CP, Aksoy E, Stender E, Willershausen B. Influence of different luting concepts on long term retentive strength of zirconia crowns. Am J Dent. 2009;22(2):122-8.

6. Della Bona A, Borba M, Benetti P, Cecchetti D. Effect of surface treatments on the Bond strenght of a zirconia: reinforced ceramic to composite resin. Braz Oral Res. 2007;21(1):10-5. doi: 10.1590/S1806-83242007000100002

7. Derand T, Molin M, Kvam K. Bond strength of composite luting cement to zirconia ceramic surfaces. Dent Mater. 2005;21(12):1158-62. doi: 10.1016/j.dental.2005.02.005

8. Kosmac T, Oblak C, Jevnikar P, Funduk N, Marion L. The effect of surface grinding and sandblasting on flexural strength and reliability of Y-TZP zirconia ceramic. Dent Mater. 1999;15(6):426433. doi: 10.1016/S0109-5641(99)00070-6

9. Lüthy $\mathrm{H}$, Loeffel $\mathrm{O}$, Hammerle $\mathrm{CH}$. Effect of thermocycling on bond strength of luting cements to zirconia ceramic. Dent Mater. 2006;22(2):195-200. doi: 10.1016/j.dental.2005.04.016

10. Oliveira AS, Ramalho ES, Ogliari FA, Moraes RR. Bonding selfadhesive resin cements to glass fibre posts: to silanate or not silanate? Int Endod J. 2011;44(8):759-763. doi: 10.1111/j.13652591.2011.01883.x

11. Kuriyama S, Terui $Y$, Higuchi D, Gotta D, Hotta $Y$, Manabe A, et al. Novel fabrication method for zirconia restorations: bonding strength of machinable ceramic to zirconia with resin cements. Dent Mater J. 2011;30(3):419-424. doi: 10.4012/dmj.2010-213

12. Radovic I, Monticelli F, Goracci C, Vulicevic ZR, Ferrari M. Selfadhesive resin cements: a literature review. J Adhes Dent. 2008;10(4):251-8.

13. Gargari M, Gloria F, Napoli And Pujia AM. Zirconia: cementation of prosthetic restorations. Literature review. Oral Implantol (Rome). 2010;3(4):25-9.

14. Guard GB, Gonçalves LS, Running AB, Moraes RR, Sinhoreti MA, Running-Sobrinho L. Luting glass ceramic restorations using the self-adhesive resin cement under different conditions dentin. J Oral Sci Appl. 2010;18(3):244-8.

15. Manso AP, Silva NR, Bonfante EA, Pegoraro TA, Days RA, Carvalho RM. Cements and adhesives for all-ceramic restorations. Dent Clin North Am. 2011;55(2):311-32. doi: 10.1016/j.cden.2011.01.011

16. Magne $\mathrm{P}$, Belser $U$. porcelain restorations adhesive in the anterior dentition. A biomimetic 1st ed approach. London: Quintessence; 2012.

17. Archegas LR, Freire, Vieira S, Caldas DB, Souza MS. Colour stability and opacity of resin cements and flowable composites for ceramic veneer luting after accelerated aging. J Dent. 2011;39(11):804-10. doi: 10.1016/j.jdent.2011.08.013

18. Magne $\mathrm{P}$, Paranhos MP, Burnett LH. New zirconia primer improves bond strength of resin-based cements. Dent Mater. 2010;26(4):345-52. doi: 10.1590/\$1678-77572010000300008

19. Aboushelib MN, Matinlinna JP, Salameh Z, Ounsi H. Innovations in bonding to zirconia-based materials:. Part I. Dent Mater. 2008;(9):1268-72. doi: 10.1016/j.dental.2008.02.010

20. Mirmohammadi $H$, Aboushelib MN, Salameh Z, Feilzer AJ, Kleverlaan CJ. Innovations in bonding to zirconia based ceramics: Part III. Phosphate monomer resin cements. Dent Mater. 2010;26(8):786-92. doi: 10.1016/j.dental.2010.04.003

21. Kelly JR, Denry I. Stabilized zirconia as a ceramic structural: an overview. Dent Mater. 2008;24(3):289-8. doi:10.1016/j. dental.2007.05.005

22. Dérand P, Dérand T. Bond strength of luting cements to zirconium oxide ceramics. Int J Prosthodont. 2000;13(2):131-5.

23. Ozcan M, Vallittu PK. Effect of surface conditioning methods on the bond strength of luting cement to ceramics. Dent Mater. 2003;19(8):725-31. doi: 10.1016/S0109-5641(03)00019-8

24. Atsu SS, Kilicarslan MA, Kucukesmen HC, Aka PS. Effect of zirconium-oxide ceramic surface treatments on the adhesive bond strength to resin. J Prosthet Dent. 2006;95(6):430-6. doi: 10.1016/j.prosdent.2006.03.016

25. Tsuo Y, Yoshida K, Atsuta M. Effects of alumina-blasting and adhesive primers on bonding between resin luting agent and zirconia ceramics. Dent Mater J. 2006;25(4):669-74. doi: 10.4012/dmj.25.669

26. Wolfart M, Lehmann F, Wolfart S, Kern M. Durability of the resin bond strength to zirconia ceramic after using different surface conditioning methods. Dent Mater. 2007;23(1):45-50. doi: 10.1016/j.dental.2005.11.040

27. Yamada K, Koizumi M, Kawamoto Y, Ishikawa $Y$, Matsumura M, Tanoue N. Effect of priming single-liquid adhesive bonding agents on to aluminum oxide of the methacrylic resin. Dent Mater J. 2007;26(5):642-6. doi: 10.4012/dmj.26.642

28. Yun JY, Ha SR, Lee JB, Kim SH. Effect of sandblasting and various metal primers on the shear bond strength of resin cement to Y-TZP ceramic. Dental Mater. 2010;26(7):650-8. doi: 10.1016/j. dental.2010.03.008

29. Zhang C, Degrange M. Shear bond strengths of selfadhesive luting resins fixing dentine to different restorative materials. J Biomater Sci Polym Ed. 2010;21(5):593-608. doi: $10.1163 / 156856209 \times 431640$

30. Miragaya L, Maia LC, EC Sabrosa, Goes MF, da Silva IN. Evaluation of self-adhesive resin cement bond strength to yttriastabilized zirconia ceramic (Y-TZP) using four surface treatments. J Adhes Dent. 2011;13(5):473-80. doi: 10.3290/j.jad.a19820

Received on: 17/10/2015 Final version resubmitted on: 17/2/2016 Approved on: 2/3/2016 